\title{
Self-esteem and anxiety in stuttering children and attitude of their parents
}

\author{
Leila Cherif ${ }^{1}$, Jaweher Boudabous ${ }^{1}$, Khawla Khmakhem ${ }^{1}$, Sourour Kammoun ${ }^{2}$, Imen Hadj kacem ${ }^{1}$, Hela Ayadi ${ }^{1}$ and Yousr Moalla $^{3}$ \\ ${ }^{1}$ Department of Child and Adolescent Psychiatry, University of Sfax, Tunisia \\ ${ }^{2}$ Department of Preventive Medicine, University of Sfax, Tunisia \\ ${ }^{3}$ Head of the department of Child and Adolescent Psychiatry, University of Sfax, Tunisia
}

\begin{abstract}
Objective: To evaluate anxiety and self-esteem in children who stutter compared to a control sample and to describe parental attitudes.

Methods: Employing a cross-sectional study, participants included 49 children who stutter and 53 controls. We have administred the State and Trait Anxiety Inventory and the Coopersmith self-esteem Inventory (the school form) to evaluate respectively anxiety symptoms and self-esteem. We have also examined parental attitudes.

Results: Compared with controls, the stuttering group showed higher levels in anxiety state ( $\mathrm{p}=0.001)$ and anxiety trait ( $\mathrm{p}=0.01$ ). Children who stutter had also a significant low self-esteem in the general domain $(\mathrm{p}=0.01)$ and in academic domain $(\mathrm{p}=0.04)$. Negative parental attitudes were significantly associated to anxiety and to poor self-esteem.

Conclusions: Stuttering appears to be associated with a heightened risk for the development of anxiety and low self-esteem. Indeed, misguided parental attitudes are risk factors for anxiety and low self-esteem. These results highlight the need for mutidisciplinary approaches on stuttering treatment including speech therapy, child psychology care and parental guidance.
\end{abstract}

\section{Introduction}

Data show that stuttering children (SC) are perceived negatively by peers [1] and are rejected by peers more often than children who do not stutter [2]. SC are often exposed to negative social experiences with both their peers and families such teasing and bullying [3]. These problems interfere negatively with self-esteem (SE) development and anxiety levels [4-9]. Anxiety has been considered for a long as one of the most frequent psychological problem associated to stuttering $[8,9,10-13]$. Indeed, some studies did not find that SC are significantly more anxious than control samples $[14,15]$. The relationship between self-esteem (SE) and stuttering has also attracted the interest of several studies $[4,5,16]$. Previous research has indicated that $\mathrm{SE}$ is an important factor in the understanding and clinical treatment of stuttering [16]. Some studies supported that stuttering negatively affects self-esteem of SC $[17,18]$ while others did not found this $[5,16]$. Familial attitudes have been also identified as risk factors associated in SC [9]. Positive parental support can help SC to manage their disorder. In contrary, negative family attitudes may hinder the development of positive management of stuttering [19].

Identifying heightened levels of anxiety and low SE as co-occurring conditions in SC helps in treatment planning and techniques, as well as parental attitudes. Therapeutic interventions for SC could often include either implicit or explicit goals to improve anxiety, low SE and parental attitudes. This support the critical need for interdisciplinary teams working with SC [20]. Screening for anxiety and low self-esteem allows a comprehensive treatment approach and a secondary prevention. Little is known about anxiety, SE and parental attitudes in SC in Tunisia. This is in contrast to the larger body of knowledge that shows the international literature. To our knowledge, there is no Tunisian study exploring this subject despite the fact that it is important. So, there is a need of minimal data that indicate a requirement for the implementation of regular clinical attention to SE, anxiety and parental attitudes in SC. This relative absence led to the current study. Thus, we aimed on this study to screen for anxiety and SE of SC compared to a control group and to analyze their associations with parental attitudes.

\section{Methods}

\section{Type of study}

A cross-sectional comparative study was conducted on two groups of children and adolescents, during a period of 2 years.

\section{Participants}

The group of children and adolescents who stutter was constituted of 49 participants drawn from the department of child psychiatry of the University Hospital Hedi Chaker in Sfax, Tunisia, when receiving speech therapy. Inclusion criteria were: (1) age 8 to 15 years, (2) presence of stuttering confirmed by speech pathologist during assessment and (3) receiving speech therapy for stuttering (4) had no concomitant disorder or illness. Exclusion criteria were: (1) no consent of parents or

${ }^{*}$ Correspondence to: Leila Cherif, Department of Child and Adolescent Psychiatry, Hedi Chaker Hospital and University of Sfax, Tunisia, E-mail: leilacherifepboukettaya@yahoo.fr

Key words: stuttering, anxiety, self-esteem, parental attitudes, children

Received: July 11, 2018; Accepted: July 31, 2018; Published: August 03, 2018 
participants, (2) children under 8 years old, (3) children older than 15 years and (4) mental retardation or psychosis disorder confirmed after child psychiatric consultation. The control group included 53 children and adolescents examined in a clinic community in Sfax for a benign acute medical condition (flu, angina, diarrhea, bronchitis, and so on). Child and adolescent psychiatrists interviewed children. Groups do not differ by sex, age and socio-economic status. The comparative table of the two groups shows this (Table 1).

\section{Measures}

\section{The State and Trait Anxiety Inventory (STAI)}

The STAI was used to measure via self-report the presence and severity of anxiety symptoms. The STAI contains two scales of 20 items each [21]. The participant responds to the STAI items by selecting one of the alternative responses using a 4-pointlikert scale. First, the State Anxiety Scale evaluates the current state of anxiety, asking how respondents feel "right now," using items that measure subjective feelings of apprehension, tension, nervousness, worry, and activation/ arousal of the autonomic nervous system. The Trait Anxiety Scale evaluates relatively stable aspects of "anxiety proneness," including general states of calmness, confidence, and security. Scores for both the State anxiety and the trait anxiety scales can vary from a minimum of 20 to a maximum of 80 .

\section{The Coopersmith self-esteem inventory (school form)}

SE was measured by Coopersmith self-esteem inventory (SEI)in its school form for the ages 8-15 years [22]. The SEI is a 58-item self-report instrument to which each subject responds "like me", or "unlike me". The Coopersmith SEI was developed through research to assess attitude toward oneself in general, and in specific contexts. The components of SE measured are: (1) General SE (26 items), related to personal worth perceptions; (2) Social SE (8 items), related to peer relationships; (3) Academic or School-Related SE (8 items), related to ability at school;
(4) Parent-related SE (8 items), related to children's status at home and parents' reactions; and (5) Total SE ranging between 0-100. Participants have good SE if they have $>18.64$ in the General self-subscale $>5.67$ in the Social Self-Peer subscale, $>4.96$ in the Home-Parents-subscale, $>4.12$ in the School-Academic subscale and $>33.35$ in the total SEI score.

The STAI and the SEI were translated into Arabic but are not yet validated in Tunisia.

\section{Evaluation of parental attitudes towards SC}

A self-report form was performed to screen for parental attitudes towards SC. We searched the literature $[13,19,23]$ for the most prevalent parental attitudes towards CS. We wanted to verify the existence of these attitudes among Tunisian parents. Parents were asked to answer yes or no to 10 questions written in dialectal Arabic, such: "Do you say to your child stop stuttering when he is speaking?", "Do you have even looked away from your child when he stutters and asked someone else?", "Do you asked your child to slow down and relax when he stutters?". Questions are summarized in (Table 2) describing parental attitudes.

\section{Procedure}

The parents of children were initially contacted on the phone and informed what the study involved. They discussed this with their child who confirmed their desire to participate. For each patient included and his parent (father or mother), a clinical interview based on predetermined format, was done by a child and adolescent psychiatrist. The interviews were held in an atmosphere of confidentiality in an examination room in the department of child psychiatry of the Hedi Chaker university hospital of Sfax. Questionnaires were selfadministered. Explanations were given for items not understood. Parents were interviewed separately about their attitudes towards their child.

Table 1. Samples presentation $(\mathrm{N}=102)$.

\begin{tabular}{|c|c|c|c|c|}
\hline \multirow{2}{*}{\multicolumn{2}{|c|}{ Socio demographic characteristics }} & \multirow{2}{*}{$\mathrm{SC}(\mathrm{N}=49)$} & Controls & \multirow{2}{*}{$\mathbf{p}$} \\
\hline & & & $(\mathrm{N}=\mathbf{5 3})$ & \\
\hline \multicolumn{2}{|l|}{ Mean age ( \pm SD) } & $10.39( \pm 2.8)$ & $10.11( \pm 1.87)$ & 0.5 \\
\hline \multirow{2}{*}{ Gender (\%) } & Boys & 77.5 & 75.4 & \multirow{2}{*}{0.8} \\
\hline & Girls & 22.5 & 24.6 & \\
\hline \multirow{3}{*}{ Socio economic status (\%) } & High & 7.6 & 16.34 & \multirow{3}{*}{0.3} \\
\hline & Middle & 79.2 & 73.46 & \\
\hline & Low & 13.2 & 10.2 & \\
\hline
\end{tabular}

SD: standard deviation

Table 2. Parental attitudes towards their SC $(\mathrm{N}=49)$

\begin{tabular}{|c|c|c|}
\hline \multirow[t]{2}{*}{ Parental attitude } & \multicolumn{2}{|c|}{ Frequency } \\
\hline & Yes $(\%)$ & No $(\%)$ \\
\hline 1) « filling in the child's words » & 57.1 & 42.9 \\
\hline 2) « asking him to slow down or relax » & 53.1 & 46.9 \\
\hline 3) « ordering him to stop stuttering! » & 44.9 & 55.1 \\
\hline 4) « manifesting impatience » & 36.7 & 63.3 \\
\hline 5) « waiting patiently » & 32.7 & 67.3 \\
\hline 6) « shouting at the child» & 26.5 & 73.5 \\
\hline 7) « looking away from the child» & 20.4 & 79.6 \\
\hline 8) «making a joke» & 10.2 & 89.8 \\
\hline 9) « hitting over the head» & 10.2 & 89.8 \\
\hline 10) « imitating » & 6 & 94 \\
\hline
\end{tabular}

Note: SC, stuttering children 


\section{Statistics}

Statistical analyses were performed by using the SPSS statistical package, version 20.0 .

Comparisons between the means of two groups were made using student's t-test. Chi-square test was used to compare percentages. All p-values are two-sided. P-values $<0.05$ were considered significant.

A descriptive study was performed for parental attitudes towards SC. Responses about parental attitudeswere recorded and analysed in the form of descriptive statistics such as frequency and percentages.

\section{Results}

\section{Demographic data for two groups}

Demographic characteristics of the two groups are presented in (Table 1). Concerning SC, the mean age of onset of stuttering was 5 years $( \pm 1.8)$. The mean duration of stuttering was 5.5 years $( \pm 3.05)$ with extremes ranging from 0 to 12 years.

\section{Screening for anxiety}

SC felt significantly more anxious than controls on the STAI state $(\mathrm{p}=0.001)$. SC had also more anxious traits, according to the STAI $(\mathrm{p}=0.01)$ (Figure 1).

\section{Self-esteem among SC and controls}

SC had significantly a low SE on the general and academic subscale than controls. No significant differences were found between the two groups on the other subscales (Figure 2).

\section{Analysis of parental attitudes on stuttering}

Table 2 shows that the most frequent parental attitudes towards SC were filling the child's words (57.1\%), asking him to slow down (53.1\%) or to stop stuttering (44.9\%), manifesting impatience and annoy $(36.7 \%)$ and looking away from the child and asking someone else (20.4\%).

\section{Associations between parental attitudes, anxiety and self- esteem of SC}

We have mentioned on (Table 3 ) only the significant associations between some parental attitudes, anxiety and SE: looking away from the child, filling in the child's words, waiting patiently and asking him to slow down or relax. The remaining parental attitudes were not significantly associated with anxiety and SE.

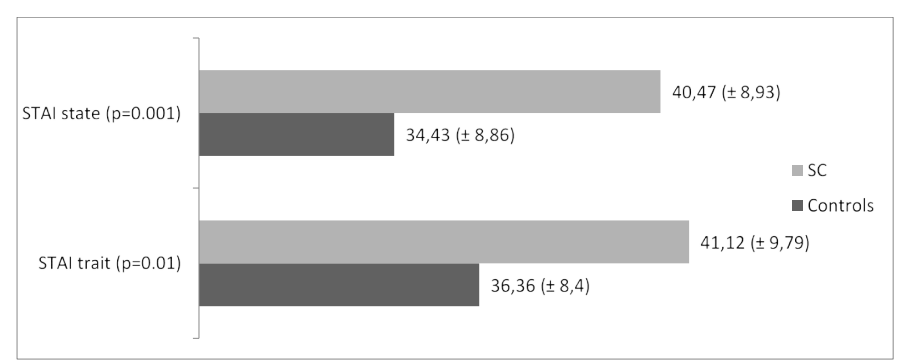

Figure 1. Comparison of anxiety according the STAI between the 2 groups (total of 102 children). STAI mean score ( \pm standard deviation): state and trait anxiety inventory $p$ value: no statistically significant correlation $(\mathrm{p}>0,05)$; significant $(0,05 \leq \mathrm{p} \leq 0.01)$; very statistically significant correlation $(\mathrm{p} \leq 0.01)$.

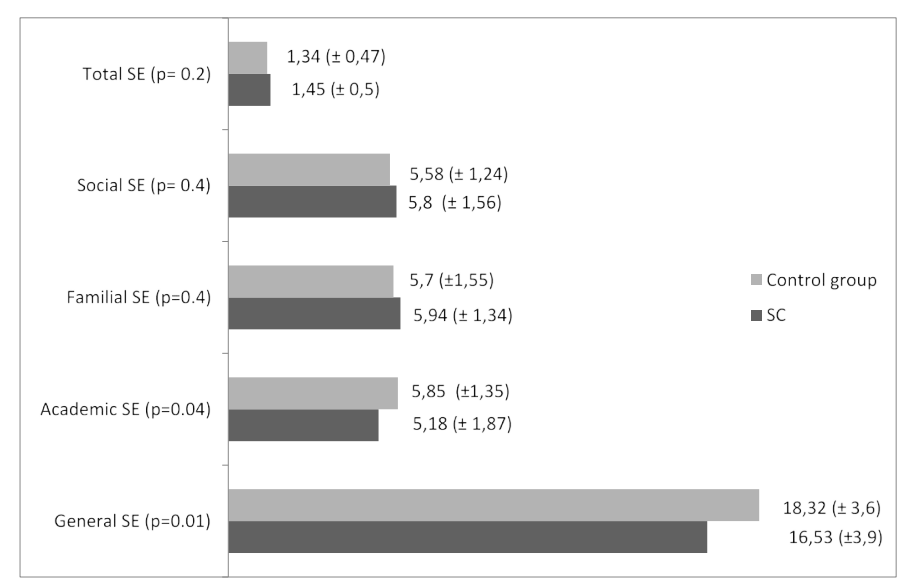

Figure 2. Comparison of average scores of SE between the 2 groups (total of 102 children) Note: SE, self-esteem mean score ( \pm standard deviation); SC, stuttering children. $p$ value: No statistically significant correlation $(\mathrm{p}>0,05)$; Significant $(0.05 \leq \mathrm{p} \leq 0.01)$; very statistically significant correlation $(\mathrm{p} \leq 0.01)$

Table 3. Correlations between parental attitudes, anxiety and SE ( $\mathrm{N}=49 \mathrm{SC})$

\begin{tabular}{|c|c|c|c|}
\hline SE domain middle score & & Parental attitude & \multirow[b]{2}{*}{$\mathrm{p}$} \\
\hline \multicolumn{3}{|c|}{ « looking away from the child» } & \\
\hline & Yes & No & \\
\hline STAI state & $47.9 \pm 8.98$ & $38.56 \pm 7.96$ & 0.002 \\
\hline STAI trait & $48.5 \pm 9.56$ & $39.23 \pm 9.02$ & 0.006 \\
\hline General SE & $13.4 \pm 3.34$ & $17.33 \pm 3.65$ & 0.003 \\
\hline Academic SE & $3.5 \pm 1.78$ & $5.62 \pm 1.66$ & 0.001 \\
\hline Total SE & $28 \pm 6.39$ & $34.72 \pm 6.58$ & 0.01 \\
\hline \multicolumn{3}{|c|}{ « filling in the child's words" } & $\mathrm{p}$ \\
\hline & Yes & No & \\
\hline Familial SE & $5.57 \pm 1.26$ & $6.43 \pm 1.32$ & 0.02 \\
\hline \multicolumn{3}{|c|}{ « waiting patiently » } & \\
\hline & Yes & No & \\
\hline Familial SE & $5.25 \pm 1.34$ & $6.27 \pm 1.23$ & 0.01 \\
\hline \multicolumn{4}{|c|}{ « asking him to slow down or relax » } \\
\hline & Yes & No & \\
\hline Academic SE & $5.73 \pm 1.56$ & $4.57 \pm 2.04$ & 0.02 \\
\hline General SE & $17.69 \pm 3.35$ & $15.22 \pm 4.13$ & 0.02 \\
\hline
\end{tabular}

Note: SE, self-esteem; STAI, State and Trait Anxiety Inventory.

$\mathrm{p}$ value: No statistically significant correlation $(\mathrm{p}>0,05)$; Significant $(0,05 \leq \mathrm{p} \leq 0,01)$; very statistically significant correlation $(\mathrm{p} \leq 0,01)$

\section{Discussion}

\section{Evaluation of anxiety among stuttering children}

There is no doubt that anxiety disorders are common on adults who stutter $[12,24,25]$, whereas they do not for children. The question if SC are anxious in general has been asked repeatedly. The answers given have been controversial. Some researchers report that anxiety is more frequent in SC compared to controls $[3,15,26]$. While other studies [27] do not find any difference between the two groups on anxiety symptoms. The current findings indicate that $\mathrm{SC}$ are more anxious than controls. First, they have more trait anxiety: an individual's general level of anxiety independent of specific threatening environments. Our research supports studies indicating that anxiety, as a trait is characteristic of person who stutter [24,28,29,30,31]. Second, in the present study, SC have more state anxiety. State anxiety in SC refers to a condition or situation-specific anxiety related to communication in general and to speech communication in particular. Scholars [32,33] have conceptualized anxiety using a multidimensional model that implies that those who score high on trait anxiety manifest greater 
state anxiety when situational stress is congruent with one of their trait anxiety levels. Our study supports the assumption that trait and state anxiety are characteristic of SC.

\section{Self esteem among children and adolescents who stutter}

Few studies have explored SE of SC. It has been argued that SE is substantially constructed based on social interactions and experiences [4]. SC can experience negative social interactions, which is hypothesized to place them at risk of having a negative impact on SE $[4,17]$. Several studies found no evidence of low SE as compared to control samples $[3,4,16]$. Other studies reported adverse effects of stuttering on SE. We shared findings that SC have low SE on the general domain $[4,18]$. The SC of our sample had not SE impairement except on the general and academic domains. We highlighted Bloodstein data according to developmental categories [34] to explain those findings. It is possible that low SE in stuttering will not be present in a child until after he reaches an advanced stage of a stutterer. General and academic SE seemed to be the first domains to be impaired.

\section{Parental attitudes toward SC}

On a study conducted in Kuwait on 424 parents in general population, the most frequent attitudes towards SC were looking away from the child (72\%), filling in the child' words (44\%) and waiting patiently (85\%) [19]. A Turkish study, exploring parental attitudes found more negative frequencies in filling the child's words, telling him to slow down, making jokes and indicating that SC should try to hide his stuttering [35]. In the present study, we found that when parents looked away from the child and asking someone else, SC were significatively more anxious and have poor SE on general and academic SE. Such parental attitudes may impact the developing of child's self esteem [23]. We found also that filling the child's word was associated with good familial SE. Nevertheless, Wischner [36], suggested that stuttering may persist because of "secondary gain" that SC often receive from others. He explained that friends and family when helping SC by speaking for him may diminish some of the negative impact.

We have noted a good familial SE on SC whose parents waited patiently during a child's stuttering. Overall, this indicates that parents are empathetic and sensitive towards their SC and highlightes the need for parental guidance on the mutidisciplinary approaches on stuttering treatment.

\section{Conclusion}

The results of this study show that anxiety and poor self esteem are more frequent in SC than in controls. Negative parental attitudes are frequent. The clinical implications of these findings are diagnostic and therapeutic. First, clinicians should screen systematically anxiety, low self-esteem and negative parental attitudes. Second, for clinicians, the issue of prioritizing treatment for co-occurring psychological difficulties becomes paramount for SC. SC who display anxiety and low self esteem could also be examined for the effectiveness of specific treatments as well as the benefits of team approaches. Treatment procedures that address the psychological concomitants of stuttering may be incorporated into fluency approaches or may stand alone. Involving family members in the therapeutic process must be an important element of treatment. It would be illusory to limit SC treatment to speech therapy. Overall management must be applied in stuttering involving psychological support, parental guidance concomitantly with speech therapy. It is crucial that professionals working with SC should be made aware in order to have an accurate understanding.

\section{Limitations}

All instruments were translated into Arabic but were not validated on the Tunisian population.

Due to the preliminary nature of these results, studies with larger samples, multiple anxiety measures and participants who have received treatment and those who have not received treatment for either their anxiety or fluency disorders appear warranted.

Our population were recruited from child psychiatry department. One of the reasons why they seek therapy might be anxiety or low self-esteem. So, anxiety and low self-esteem might be overrepresented. Therefore, it is suggested to include in future research SC that were not followed by a child psychiatrist.

\section{References}

1. Langevin M, Hagler P (2004) Development of a scale to measure peer attitude toward children who stutter. In EvidenceBased Treatment of Stuttering. Empirical Issues and Clinical Implications (ed. A. K. Bothe), Mahwah, NJ: Lawrence Erlbaum Associates pp. 139-171.

2. Davis S, Howell P, Cooke F (2002). Sociodynamic relationships between children who stutter and their non-stuttering classmates. J Child Psychol Psychiatry 43: 939-947. [Crossref]

3. Blood GW, Blood IM (2007). Preliminary study of self-reported experience of physical aggression and bullying of boyswho stutter: relation to increased anxiety. Percept Mot Skills 104: 1060-1066. [Crossref]

4. Adriaensens S, Beyers W, Struyf E (2015) Impact of stuttering severity on adolescents domain-specific and general self-esteem through cognitive and emotional mediating processes. Journal of Communication Disorders 58: 43-57.

5. Blood GW, Blood IM (2004) Bullying in adolescents who stutter: communicative experience and self-esteem. Contemporary issues in communication science and disorders 31: 69-79.

6. Erickson S, Block S (2013) The social and communication impact of stuttering on adolescents and their families. J Fluency Disord 38: 311-324. [Crossref]

7. Mulcahy K, Hennessey N, Beilby J, Byrnes M (2008) Social anxiety and the severity and typography of stutteringin adolescents. J Fluency Disord 33: 306-319.

8. Reilly S, Onslow M, Packman A, Wake M, Bavin EL, et al. (2009) Predicting stuttering onset by the age of 3 years: A prospective, community cohort study. Pediatrics 123: 270-277. [Crossref]

9. Smith KA, Iverach L, O'Briand S, Kefalianosa E, Reilly S (2014) Anxiety of children and adolescents who stutter: A review. J Fluency Disord 40: 22-34. [Crossref]

10. Beitchman J, Wilson B, Johnson C, Atkinson L, Young A, et al. (2001) Fourteen-year follow-up of speech/language impaired and control children: Psychiatric outcome. $J$ Am Acad Child Adolesc Psychiatry 40: 75-82.

11. Broeren S, Newall C, Dodd HF, Locker R, Hudson JL (2014) Longitudina investigation of the role of temperament and stressful life events inchildhood anxiety. Dev Psychopathol 1-13. [Crossref]

12. Iverach L, Menzies RG, O'Brian S, Packman A, Onslowa M (2011) Anxiety and Stuttering: Continuingto Explore a Complex Relationship. Am J Speech Lang Pathol 20: 221-232. [Crossref]

13. Lau SR, Beilby JM, Byrnes ML, Hennessey NW (2012) Parenting styles and attachment in school-aged children who stutter. J Commun Disord 45: 98-110. [Crossref]

14. Van der Merwe B, Robb MP, Lewis JG, Ormond T (2011) Anxiety measures and salivary cortisol responses in preschool children who stutter. Contemporary issues in communication science and disorders 38: 1-10.

15. Vinacoura RE, Levin I (2004) The relationship between anxiety and stuttering: a multidimensional approach. J Fluency Disord 29: 135-148. [Crossref]

16. Yovetich WS, Leschied AW, Flicht J (2000) Self-esteem of school-age children who stutter. J Fluency Disord 25: 143-153.

17. Pearson JC, Child JT, DeGreeff BL, Semlak JL, Burnett A (2011) The influence of biological sex, self-esteem, and communication apprehension on unwillingness to communicate. Atl J Communication 19: 216-227. 
18. Zuckner H (2011) Self-esteem of children and adolescents who stutter - Impact on speech behaviour and stuttering experience. Sprache-Stimme-Gehor 35: E77-E86.

19. Al-Khaledi M, Lincolna M, McCabe P, Packman A, Alshatti T (2009) The attitudes, knowledge and beliefs of Arab parents in Kuwait about stuttering. J Fluency Disord 34: 44-59. [Crossref]

20. Ezrati-Vinacour R, Levin I (2004) The relationship between anxiety and stuttering: a multidimensional approach. J Fluency Disord 29: 135-148. [Crossref]

21. Spielberger C, Gorsuch RL, Lushene R, Vagg PR, Jacobs GA (1983) Manual for the state-trait anxiety inventory. Palo Alto, CA: Consulting Psychological Press.

22. Coopersmith S (1967) The antecedents of self-esteem. San Francisco, CA: W.H. Freeman.

23. Langevin M, Packman A, Onslow M (2010) Parent perceptions of the impact of stuttering on their preschoolers and themselves. J Commun Disord 43: 407-423. [Crossref]

24. Craig A, Hancock K, Tran Y, Craig M (2003) Anxiety levels in people who stutter:A randomized population study. J Speech Lang Hear Res 46: 1197-1206. [Crossref]

25. Kraaimaat TW, Vanryckeghem M, van Dam-Baggen R (2002) Stuttering and social anxiety. J Fluency Disord 27: 319-331.

26. Blood GW, Blood IM, Maloney K, Meyer C, Qualls CD (2007) Anxiety levels in adolescents who stutter. J Commun Disord 40: 452-469. [Crossref]

27. Davis S, Shisca D, Howell P (2007) Anxiety in speakers who persist and recover from stuttering. J Commun Disord 40: 398-417. [Crossref]
28. Barbara DA (1960) The psychodynamics of stuttering. In D. A. Barbara (Edn.), Psychological and psychiatric aspects of speech and hearing. Springfield: Charles C. Thomas.

29. Caruso AJ, Chodzko-Zajko WJ, Bidinger DA, Sommers RK (1994) Adults who stutter: responses to cognitive stress. $J$ Speech Hear Res 37: 746-754. [Crossref]

30. Craig A (1990) An investigation into the relationship between anxiety and stuttering. Journal of Speech and Hearing Disorders 55: 290-294.

31. Fitzgerald HE, Djurdjic SD, Maguin E (1992) Assessment of sensitivity to interpersonal stress in stutterers. J Fluency Disord 25: 31-42.

32. Endler NS, Edwards JM, Vitelli R (1991) Endler Multidimensionality Anxiety Scales (EMAS): Manual. Los Angeles: Western Psychological Services.

33. Endler NS, Parker JDA, Bagby RM, Cox BJ (1991) Multidimensionality of state and trait anxiety factor structure of the Endler Multidimensionality Anxiety Scales. J Pers Soc Psychol 60: 919-926. [Crossref]

34. Bloodstein O (1995) A handbook on stuttering (3rd Edn) San Diego.

35. Sertan Ö, Kenneth SL, Seyhun T (2011) Stuttering attitudes among Turkish family generations and neighbors from representative samples. J Fluency Disord 36: 318-333. [Crossref]

36. Wischner George J (1952) Experimental approach to expectancy and anxiety in stuttering behaviour. Journal of Speech and Hearing Disorders 17, 139-154.

Copyright: $\odot 2018$ Cherif L. This is an open-access article distributed under the terms of the Creative Commons Attribution License, which permits unrestricted use, distribution, and reproduction in any medium, provided the original author and source are credited. 